\title{
REPERTÓRIO DE PESQUISA SOBRE A EDUCAÇÃO RURAL NO PARANÁ POR MEIO DA IMPRENSA (1930-1961)
}

\author{
REPERTORIO DE INVESTIGACIÓN RURAL EN PARANÁ A TRAVÉS DE LA \\ PRENSA (1930-1961)
}

\author{
RESEARCH REPERTOIRE ON RURAL EDUCATION IN PARANA THROUGH THE \\ PRESS (1930-1961)
}

\author{
Simone Burioli IVASHITA ${ }^{1}$
}

RESUMO: O presente texto é resultado de pesquisa de pós-doutoramento e teve como objetivo geral localizar, catalogar e analisar jornais, revistas e boletins que tratam da educação rural no estado do Paraná disponibilizados na Biblioteca Nacional no período de 1930 a 1961. Para tanto, foram mapeados os artigos sobre educação rural presentes em periódicos científicos, considerando as recorrências temáticas, o que foi apresentado em forma de repertório. Como principais resultados podemos destacar que as temáticas centrais encontradas foram na formação do professor rural, em eventos destinados à temática da educação rural, na função e representação da educação rural e a permanência do homem no campo. Nos periódicos há uma relativa preocupação com o rural (ou a ausência de abordagem desta temática) ligada ao movimento político, indicando se o governante era um típico ruralista ou um defensor da industrialização.

PALAVRAS-CHAVE: História da educação. Educação rural. Imprensa paranaense.

RESUMEN: El presente texto es el resultado de uma investigación posdoctoral y tenía el objetivo general de localizar, catalogar y analizar periódicos, revistas y boletines informativos sobre educación rural en el Estado de Paraná, que se pusieron a disposición em la Biblioteca Nacional de 1930 a 1961. Para este propósito, se mapearon los artículos sobre la educación rural que aparece em publicaciones periódicas teniendo en cuenta las recurrencias temáticas, que se presentó em forma de repertorio. Como resultados principales, podemos destacar que los temas centrales encontrados fueron en la capacitación de docentes rurales, en eventos dirigidos a la educación rural, el papel y la representación rural y la permanencia del hombre en el campo. En las publicaciones periódicas existe uma preocupación relativa por lo rural (o la falta de enfoque de este tema) vinculado al movimento político, lo que indica si el gobernante era um ruralista típico o um defensor de la industrialización.

PALABRAS CLAVE: Historia de la educación. Educación rural. Prensa paranaense.

${ }^{1}$ Universidade Estadual de Londrina (UEL), Londrina - PR - Brasil. Professora Adjunta do Departamento de Educação e do Programa de Pós-Graduação em Educação (UEL). Doutorado em Educação (UEM). ORCID: https://orcid.org/0000-0002-8766-8331. E-mail: prof.simone@uel.br

RIAEE - Revista Ibero-Americana de Estudos em Educação, Araraquara, v. 16, n. 4, p. 2663-2681, out./dez. 2021. e-ISSN: 1982-5587 
ABSTRACT: The present text is the result of post-doctoral research and had the general objective of locating, cataloging and analyzing newspapers, magazines and newsletters dealing with rural education in the state of Parana made available at the National Library from 1930 to 1961. For this purpose, articles on about rural education that appear in scientific periodicals considering thematic recurrences were mapped, which was presented in the form of a repertoire. As main results we can highlight that the central themes found were rural teacher formation, events aimed at rural education, the role and representation of rural education and the permanence of men in the field. In the periodicals there is a relative concern with the rural (or the lack of approach to this theme) linked to the political movement, indicating whether the ruler was a typical ruralist or a defender of industrialization.

KEYWORDS: History of education. Rural education. Paraná press.

\section{Introdução}

O estado do Paraná foi um estado predominantemente rural até meados de 1960, e isso indica a importância da educação no meio rural, permitindo problematizar a função da escola neste cenário, sua organização e a formação de seus professores. De modo geral, as escolas localizadas no campo, naquele momento, tinham por função educar o homem do campo, tendo como uma das finalidades mantê-lo ali, ou seja, seria uma escola que serve ao seu meio.

Nesta época, tanto no estado do Paraná como em outras localidades do país, acontecia o movimento do ruralismo pedagógico, que propunha dentre outras coisas a escola integrada às condições locais, e para isso incentivava a fixação do homem ao campo.

A fase de (re)ocupação do território paranaense implicava povoamento, movimentos migratórios, construção da malha rodoviária, que juntamente com a produção cafeeira queria consolidar o estado como maior produtor e exportador de café do Brasil, portanto, a expansão econômica do estado não se deu pela indústria, mas sim pela lavoura, tendo o café como principal protagonista; nas palavras de Schelbauer e Correia (2013, p. 3): “a expansão agrícola e escolar está sobremaneira vinculada a atuação do poder público estatal em estreita relação com o federal, principalmente nos governos de Manoel Ribas e Moysés Lupion”.

A colonização das áreas rurais e as demais características elencadas acima fazem parte do discurso que foi conjecturado pelas pessoas da época, indicando um período de desenvolvimento ligado à ideia de progresso e modernização, no qual a educação foi sublinhada como um dos fatores desta modernidade. A autora entende que a escola primária no meio rural foi estruturada como uma política estadual porque se preocupava em primeiro lugar com a "formação das novas gerações que pudessem garantir a riqueza do Estado e o segundo, civilizar a população que habitava no meio rural, ensinar não só a ler, escrever e 
contar, mas hábitos de higiene e valorização da vida no campo" (SCHELBAUER, 2014, p. 79).

A industrialização no estado favorecia a expansão da escola primária para o interior, por meio de várias modalidades. Entretanto, esta expansão não foi acompanhada da necessária formação de professores para atuar nas escolas edificadas: tal formação ${ }^{2}$ tinha que ser buscada na capital, Curitiba, ou em outros estados, como Santa Catarina, conforme tratado por Correia (2013).

É importante indicar que a expansão da escola primária ocorreu de diferentes maneiras e de modo crescente, apoiada em bases ideológicas distintas, conforme afirmam Schelbauer e Correa (2013). Em termos educacionais ela se dá sob a orientação da Educação Nova, a partir de 1930.

No ano de 1942 aconteceu o VIII Congresso Brasileiro de Educação, realizado pela Associação Brasileira de Educação (ABE) na cidade de Goiânia/GO, que alavancou a discussão sobre a dualidade de formação do professorado, se devia priorizar a formação para atuação em uma escola única ou em uma escola diversificada.

Diante dessa expansão da escola primária rural no estado do Paraná, em consonância com a extensão econômica e política, faz necessária uma investigação mais detida acerca da representatividade da educação rural na escolarização paranaense. Podemos fazer isso por muitos vieses, neste texto especificamente optamos pelo olhar da imprensa.

Trabalhar com a imprensa possibilita ao menos duas diretrizes de pesquisa: podemos vislumbrá-las como uma horizontalização e uma verticalização da investigação, delineadas com e a partir da imprensa, e que justifica nossa opção pelo repertório:

[...] de um lado, o estabelecimento de repertórios destinados a informar sobre o conteúdo dos periódicos, classificando-os, organizando seu índice temático e registrando seu ciclo de vida. Tais repertórios fornecem materiais básicos: dados de partida que permitem a localização de informações para pesquisas sobre a história da educação, das práticas escolares ou do sistema de ensino. Evidentemente, a partir daí, uma outra diretriz de trabalho se configura e o estudo dos próprios periódicos permite situar o movimento de grupos de professores, mapear diferentes atuações, detectar disputas e, assim, explicitar em parte o funcionamento do campo educacional (CATANI; SOUSA, 1994, p. 178)

Ainda de acordo com as autoras, trabalhar com pesquisas de mapeamento e repertório contribui para localizar e sistematizar dados ou informações que ajudam a superar os limites

${ }^{2}$ Importante indicar que o Curso Normal Regional foi instituído pela Lei Orgânica do Ensino Normal, Decreto n. 8.530, de 2 de janeiro de 1946, e tinha a duração de quatro anos. Tal lei atingia também a formação do professor para atuar no espaço rural. Para saber mais ver tese de Thais Bento Faria (2017). 
da pesquisa no Brasil no que diz respeito ao acesso, à catalogação e à conservação de fontes. Este tipo de pesquisa evita ainda a duplicidade de trabalho entre os pesquisadores, incentivando a continuidade nas investigações e, ainda, potencializando o uso de materiais já explorados (CATANI; SOUSA, 1994; 2001).

A iniciativa de elaborar repertórios partiu do francês Pierre Caspard ${ }^{3}$ (1991) e do português António Novoa ${ }^{4}$, que divulgaram o resultado de suas pesquisas no livro "A imprensa de educação e ensino: Repertório Analítico (séculos XIX e XX)”, publicado em Lisboa em 1993, e também no capítulo publicado no livro "Educação em Revista" organizado por Denice Barbara Catani e Maria Helena Câmara Bastos (2002).

No Brasil, na $15^{\mathrm{a}}$ Reunião Anual da Associação Nacional de Pós-Graduação de Pesquisa em Educação, realizada em Caxambu (MG), Catani e Sousa $\left(1992^{5}\right)$, já propunham a organização de repertórios analíticos e catálogos ${ }^{6}$ de referências para avançar os limites do acesso às fontes de pesquisa. As autoras assinalavam que:

[...] a possibilidade de desenvolver o trabalho com e a partir da imprensa pedagógica periódica norteando-se por duas diretrizes. A primeira delas, constitui-se pela investigação que visa estabelecer a história seria e repertórios analíticos destinados a informar sobre o conteúdo dos periódicos, classificando-os, registrando seu ciclo de vida, predominâncias e recorrências temáticas e informações sobre produtores, colaboradores e leitores, entre outros dados. Tais repertórios podem fornecer materiais básicos, dados que funcionam como ponto de partida para a localização de informações para pesquisas sobre História da Educação, das práticas e das disciplinas escolares dos sistemas de ensino. Além disso, uma outra diretriz de trabalho se configura pelo estudo específico e "interno" ao próprio periódico e sua produção [...] (CATANI; SOUSA, 2001, p. 242).

O repertório que foi constituído a partir da pesquisa de pós-doutoramento destina-se a facilitar o acesso à imprensa paranaense como fonte de pesquisa, tomando como recorte as questões ligadas ao universo rural.

3 O Repertoire Analytique, investigação realizada por Pierre Caspard na França, intitulada La presse d'education et d'enseignement. Repertoire analytique XVIII siécle - 1940, trata do que ele denomina de imprensa de ensino (e não imprensa pedagógica), e pode ser tomado como um trabalho pioneiro indicando a outros pesquisadores a riqueza material presente nos impressos.

${ }^{4}$ Inspirado pelo trabalho francês, elaborou um repertório analítico português, e se valeu da mesma nomenclatura - imprensa de educação e ensino. Ambos os trabalhos objetivam ampliar o corpus da imprensa de educação e ensino, não se restringindo apenas à imprensa pedagógica.

${ }^{5}$ Posteriormente este trabalho foi publicado em forma de artigo na Revista do Instituto de Estudos Brasileiros, 37, 177-183, 1994. Disponível em: http:/www.revistas.usp.br/rieb/article/view/71310. Acesso em: 10 jun. 2020.

${ }^{6}$ Em relação aos catálogos temos o trabalho de CAMARGO, Ana Maria de Almeida. A imprensa periódica como objeto de instrumento de trabalho: catálogo da hemeroteca Júlio de Mesquita do Instituto Histórico e Geográfico de São Paulo, 1975. Dissertação (mestrado em História), Universidade de São Paulo.

RIAEE - Revista Ibero-Americana de Estudos em Educação, Araraquara, v. 16, n. 4, p. 2663-2681, out./dez. 2021. e-ISSN: 1982-5587 


\section{Referencial Teórico Metodológico}

Para a construção desse estudo investigativo foi adotado como procedimento metodológico a pesquisa documental, realizada por meio dos periódicos disponíveis na Hemeroteca Digital da Biblioteca Nacional, circunscrevendo o recorte temporal ao estado do Paraná.

De acordo com Gil (2002, p. 62-3), a pesquisa documental apresenta algumas vantagens por ser "fonte rica estável de dados", isso se traduz em um tipo de pesquisa que não implica altos custos, não exige contato com os sujeitos da pesquisa e permite uma leitura arraigada das fontes. Ela se aproxima da pesquisa bibliográfica, entretanto o que as diferencia é a natureza das fontes.

A pesquisa na base de dados da Hemeroteca se deu por meio das palavras de busca ligadas ao rural: educação rural, escola rural, professor/a rural. As matérias encontradas foram catalogadas e classificadas levando em consideração algumas preocupações que apareciam com mais recorrência na imprensa: formação de professores para atuar no meio rural; função e representação da escola rural; organização da educação rural, eventos ligados à temática e a importância do homem do campo permanecer no ambiente rural. O conteúdo das matérias é apresentado e discutido na sessão seguinte e sublinha a preocupação com a questão rural no estado do Paraná, entre as décadas de 1930 e 1960, quando este território era predominantemente rural.

Os estudos que se valem da imprensa como referência para compreender a educação e a sociedade, de modo geral, tem se avolumado muito nos últimos anos, especificamente no campo da História da Educação. Ao se dedicar a este novo tipo de fonte $^{7}$ os historiadores da educação alargam a compreensão do campo educativo sobre a produção do conhecimento acerca da educação, a circulação de ideias e modelos educativos, por meio de muitos olhares. Como aponta Nóvoa (2002, p. 30-31):

Na verdade, é difícil encontrar um outro corpus documental que traduza com tanta riqueza os debates, os anseios, as desilusões e as utopias que têm marcado o projeto educativo nos últimos dois séculos. Todos os atores estão presentes nos jornais e nas revistas: os alunos, os professores, os pais, os políticos, as comunidades... As suas páginas revelam, quase sempre "a quente", as questões essenciais que atravessam o campo educativo numa determinada época.

7 É preciso indicar que o tipo de fonte não é novo especificamente, mas sim, sua forma de utilizá-la. Anteriormente os pesquisadores não davam a devida importância à imprensa como objeto de investigação, utilizando-se dela apenas como fonte para confirmar as análises apoiadas em outro tipo de documentação. 
O mesmo autor destaca que é por meio da imprensa que é possível perceber as alterações no campo da educação ao longo dos períodos históricos. Isso fica evidente na forma como as informações aparecem nos periódicos, que de alguma forma expressam a realidade escolar, proporcionando análises de diferentes componentes e protagonistas da escola. A imprensa traz dados que compõem a prática escolar, pois "é difícil imaginar um meio mais útil para compreender as relações entre a teoria e a prática, entre os projetos e as realidades, entre a tradição e inovação [...]” (NÓVOA, 2002, p. 31).

Sabemos da importância das instituições formais na transmissão da cultura de geração em geração, mas é inegável que outras instâncias também participam do processo educativo, como os romances, jornais, revistas, teatro, pintura etc., e indicam que tem muito a dizer sobre a forma como as culturas são produzidas, conservadas e/ou transformadas (PALLARESBURKE, 1998). A mesma autora destaca que a imprensa periódica, primeiro na Europa e depois no restante do mundo ${ }^{8}$, foi tomando um veio mais cultural do que noticioso e assumiu assim a função de agente cultural, mobilizando opiniões e disseminando idéias.

O uso da imprensa como fonte e objeto de pesquisa vem se alargando paulatinamente, principalmente pelo seu caráter imediato, pois as reflexões que aparecem nos impressos estão muito próximas dos acontecimentos. A imprensa, especializada ou não, também pode ser entendida como palco de manifestações coletivas, onde podem ser identificados debates, discussões e disputas de determinada época. A imprensa periódica diária e popular pode ser escrita por leigos, mesmo que aborde temas educacionais, e ainda assim serve de fonte para a pesquisa histórica, dado que apresenta projetos políticos, debates da sociedade e os problemas de cada época.

Ao analisar a imprensa é possível identificar discursos que articulam teorias e práticas, que podemos situar no nível macro do sistema. Importante também a mudança de perspectiva, voltando os olhos para o plano micro da experiência concreta (NÓVOA, 2002). Essa análise que dilata e retrai permite compreender o movimento histórico dos caminhos que a educação percorreu no Brasil, e que foram registrados pela imprensa.

A diversidade de fontes ligadas à imprensa é enorme, mas as mais promissoras são aquelas que tratam especificamente das publicações voltadas diretamente para as questões educacionais. $\mathrm{O}$ estudo da imprensa periódica especializada em educação traz sempre profuso material que permite acarear as práticas e as disciplinas escolares, pois apresenta subsídios

${ }^{8}$ Este processo demorou um pouco mais no Brasil, porque até o século XIX, a imprensa por aqui não era autorizada. Foi só em 1808, com a chegada da família real, que a imprensa foi implantada e utilizada oficialmente, por meio do jornal A Gazeta do Rio de Janeiro, órgão do governo. 
úteis para a compreensão histórica do sistema de ensino, colocando no foco das investigações a cultura escolar brasileira.

Além disso, este viés investigativo desvela questões ligadas ao trabalho docente, às apropriações da lei e das políticas governamentais, a prática docente, aos métodos e técnicas utilizadas no espaço escolar, bem como a organização da escola. Catani (1996, p. 117) sistematiza a abrangência do estudo da imprensa pedagógica assim:

[...] as revistas especializadas em educação, no Brasil e em outros países, de modo geral constituem uma instância privilegiada para a apreensão dos modos de funcionamento do campo educacional enquanto fazem circular informações sobre o trabalho pedagógico e o aperfeiçoamento das práticas docentes, o ensino específico das disciplinas, a organização dos sistemas, as reivindicações da categoria do magistério e outros temas que emergem do espaço profissional. Por outro lado, acompanhar o aparecimento e o ciclo de vida dessas revistas permite conhecer as lutas por legitimidade, que se travam no campo educacional. É possível analisar a participação dos agentes produtores do periódico na organização do sistema de ensino e na elaboração dos discursos que visam a instaurar as práticas exemplares.

Dentro da temática da imprensa, portanto, contamos com uma especificidade ligada às questões educacionais. A imprensa pedagógica é aquela que dispõe de orientação ao magistério, como guia prático do cotidiano educacional e escolar, “[...] fazem circular informações sobre o trabalho pedagógico e o aperfeiçoamento das práticas educativas, o ensino específico das disciplinas, a organização dos sistemas, as reivindicações dos professores" (FERNANDES, 2008, p. 16). Algumas das pesquisadoras que têm se dedicado ao estudo da imprensa pedagógica brasileira são: Maria Helena Camara Bastos (1994), Marta Maria Chagas de Carvalho (1994), Decice Barbara Catani (1989, 1996), entre outras.

A tese de doutorado de Denice Catani (1989), intitulada Educadores à meia-luz: um estudo da Revista de Ensino da Associação Beneficente do Professorado Público de São Paulo (1902-1918), é um marco dentre os trabalhos que olham o periódico pelo lado “interno", a partir da reconstrução do ciclo de vida deste, verticalizando a análise.

A imprensa pedagógica como fonte auxilia no conhecimento da organização pretendida para o universo escolar, seus sujeitos, práticas e saberes postos em circulação. Ela pode ser reconhecida por permitir questionamentos e reflexões aos pesquisadores, pois:

Evidencia as diretrizes oficiais que a escola recebe e necessita atender e ao mesmo tempo permite a identificação de outros fatores integrantes da construção do que denominamos espaço escolar, ou seja, os pontos de confluência que compõe as diversas facetas registradas no impresso. Tomando por base o que está registrado no impresso, pode-se ampliar a compreensão que se tem construída acerca do universo escolar, adentrando o 
ensino e suas características por perspectivas outras, diferentes daquelas consideradas consolidadas. (RODRIGUES, 2010, p. 313).

Desta forma, o pesquisador deve estar atento aos outros elementos referentes não só à construção do texto que analisa, mas às questões exteriores, como a constituição do impresso, o contexto histórico em que o impresso está inserido, a circulação, a ortografia utilizada à época, o clima político e o público consumidor. O uso de impressos como fonte implica em analisá-los como objetos que possuem materialidade, contextos e conteúdos próprios.

Outra forma de trabalhar com os impressos é a constituição de repertórios, e o trabalho de referência aqui no Brasil foi organizado por Denice Barbara Catani e Cynthia Pereira de Souza (1999), intitulado Catálogo da Imprensa Periódica Educacional Paulista (1890-1996). Anteriormente, fora do Brasil, este trabalho já estava sendo feito, como já citado anteriormente nos repertórios franceses e portugueses.

O livro cujo título é Educação em revista - a imprensa periódica e a história da educação foi organizado por Denice Barbara Catani e Maria Helena Camara Bastos e publicado em 2002; demonstra o resultado de pesquisas nacionais e internacionais que analisam periódicos em diferentes perspectivas, como fonte para a pesquisa em História da Educação.

Durante a análise dos periódicos tomamos como referencial teórico as contribuições elaboradas pela História Cultural por meio do conceito de representação ${ }^{9}$ (CHARTIER, 1990) sobre a educação rural que aparece nos periódicos, sustentando a circulação de ideias sobre a temática no estado do Paraná.

\section{Resultados e Discussões}

A opção por apresentar os resultados da pesquisa em formato de repertório indica ao menos algumas considerações: a necessidade de produzir um instrumento que facilite o acesso às fontes; o reconhecimento da imprensa como um objeto/fonte importante para a historiografia da educação e o intento de contribuir para a ampliação do campo epistemológico da História da Educação.

O repertório permite vislumbrar a riqueza de matérias acerca da questão rural no estado do Paraná, publicadas em jornais sem o viés da imprensa pedagógica necessariamente,

\footnotetext{
${ }^{9}$ Representação aqui é entendida como a apresentação pública de algo ou de alguém, como um elemento que possibilita "ver uma coisa ausente", tornando possível a "exibição de uma presença" (CHARTIER, 1990, p. 23). A representação é uma forma de cristalizar, ilustrar, simbolizar uma ideia. Para o autor, as representações culturais são articuladas aos interesses dos grupos sociais, portanto, a representação de educação rural que aparece nos periódicos de alguma forma indica o que a sociedade paranaense entende deste conceito.
} 
e organiza um conjunto de impressos que constituem uma via privilegiada de acesso às fontes que tomam por objeto a imprensa.

O material que foi compilado no repertório confirma a possibilidade de abordar os temas ligados à questão do rural $^{10}$ sob muitas perspectivas: a formação do professor rural, eventos destinados à temática, função e representação da escola rural, a organização da educação rural, fixação do homem ao campo, a preocupação com o rural (ou a ausência de abordagem desta temática) ligada ao movimento político, indicando se o governante era um típico ruralista ou um defensor da industrialização. Essas são algumas das categorias que vamos explorar para apresentação do repertório.

Quadro 1 - síntese do repertório dos dados coletados, 1930-1953

\begin{tabular}{|c|c|c|}
\hline Categoria & Periódico & Ano/reportagem \\
\hline \multirow[t]{4}{*}{$\begin{array}{l}\text { Formação do professor } \\
\text { rural }\end{array}$} & O Dia & $\begin{array}{l}1932 \text { - Renovação dos quadros do magistério, Bases } \\
\text { para a Organização do ensino complementar, normal, e } \\
\text { normal superior }\end{array}$ \\
\hline & Diário da Tarde & $\begin{array}{l}1930 \text { - Curso profissional rural } \\
1934 \text { - Os clubs agrícolas escolares da sociedade dos } \\
\text { amigos de Alberto Torres }\end{array}$ \\
\hline & Rio Negrenser Zeitung & 1943 - Professorinha \\
\hline & Diário do Paraná & 1947 - Universidade Rural e Técnica do Paraná \\
\hline \multirow[t]{5}{*}{ Eventos } & O Dia & $\begin{array}{l}1934 \text { - Congresso de Educação Rural } \\
1937 \text { - Congresso de ensino rural promovido pela } \\
\text { Sociedade Luiz Pereira Barreto }\end{array}$ \\
\hline & Rio Negrenser Zeitung & 1942 - Oitavo Congresso Brasileiro de Educação \\
\hline & Paraná Norte ${ }^{11}$ & 1948 - Semana Ruralista de Londrina \\
\hline & A Tarde & 1950 - Seminário da Educação Rural \\
\hline & A Divulgação & 1953 - II Conferência Rural Brasileira \\
\hline $\begin{array}{l}\text { Função e representação da } \\
\text { escola rural }\end{array}$ & O Estado & 1936 - A função da escola rural \\
\hline \multirow[t]{3}{*}{$\begin{array}{l}\text { Organização da educação } \\
\text { rural }\end{array}$} & O Dia & $\begin{array}{l}1932 \text { - O ensino agrícola nas escolas ruraes, Educação } \\
\text { rural, A educação nova emação } \\
1934 \text { - O ensino rural } \\
1935 \text { - A Educação rural no Brasil } \\
1938 \text { - A educação rural na campanha da } \\
\text { desanalfabetização }\end{array}$ \\
\hline & O Estado & $\begin{array}{l}1936 \text { - O porquê do ensino rural } \\
1937 \text { - Como é o que já fez a escola de trabalhadores } \\
\text { rurais }\end{array}$ \\
\hline & A Divulgação & 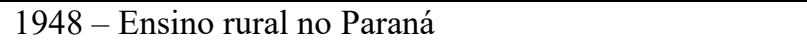 \\
\hline
\end{tabular}

${ }^{10}$ Em alguns periódicos analisado no período não foram localizados nada sobre a questão da educação rural, são eles: Ilustração paranaense (1927 a 1981); A Tarde (1930 a 1960); Joaquim (1946 a 1948); União (1948); GranFina (1940 a 1942); Maestro Bento Mossununga (1898 a 1979); Correio da Noite (1959 a 1960); Última Hora (1959-1964).

${ }^{11}$ Sobre o Paraná Norte há uma dissertação que discute o jornal especificamente na região de Londrina, trata-se do trabalho de CAMARGO, Fernanda Silva. Educação no jornal Paraná-Norte da cidade de Londrina (1934-1953). Dissertação (Mestrado em educação). Universidade Estadual de Londrina, Londrina, 2018 e também artigo publicado na revista Cadernos de História da Educação, v 19, n1 de 2020, intitulado Jornal Paraná-Norte: educação na cidade de Londrina (1934-1953), disponível em: $<$ http://www.seer.ufu.br/index.php/che/article/view/52702/28155> 


\begin{tabular}{|c|c|c|}
\hline & Diário do Paraná & $\begin{array}{l}1946 \text { - Acordo para o auxílio as escolas rurais } 1947 \text { - } \\
\text { Comentário sobre a lei orgânica do ensino agrícola }\end{array}$ \\
\hline & Paraná Norte & $\begin{array}{l}1949 \text { - A campanha de Educação de Adultos na zona } \\
\text { rural } \\
1950 \text { - Uma escola rural para Londrina }\end{array}$ \\
\hline & Paraná Esportivo & 1953 - O Esporte nas escolas de trabalhadores rurais \\
\hline \multirow[t]{2}{*}{$\begin{array}{l}\text { Fixação do homem ao } \\
\text { campo }\end{array}$} & O Dia & $\begin{array}{l}1930 \text { - A educação do lavrador precisa do auxílio da } \\
\text { nação inteira; A Semana de Educação } \\
1937 \text { - Criar escolas e abrir estradas }\end{array}$ \\
\hline & Paraná Norte & $\begin{array}{l}1950 \text { - Verdadeiro levantamento das necessidades das } \\
\text { populações rurais }\end{array}$ \\
\hline
\end{tabular}

Fonte: Elaborado pela autora

No que tange à Formação do professor rural temos explicitado no jornal O Dia ${ }^{12}$ (1932 edição $\mathrm{n}^{0}$. 2606) onde há uma discussão sempre presente no cenário educacional paranaense que é a Renovação dos quadros do magistério, matéria escrita por Raul Rodrigues Gomes ${ }^{13}$. $\mathrm{Na}$ intenção de renovar o quadro do magistério e substituir as professoras leigas por professoras normalistas, surge uma proposta para evitar as acusações de abusos no provimento das cadeiras, a dificuldade se dava principalmente porque havia uma escassez de diplomadas, e as que existiam preferiam as "delícias do asfalto à aspereza da existência rural".

A matéria indica que o que havia eram moças feitas, sem o mínimo de preparo intelectual ou técnico ou ainda meninas "mal saídas dos terceiros ou quartos anos primários", com este perfil elas só podiam causar prejuízo ao ensino, à disciplina e até à moralidade. $\mathrm{O}$ comportamento a partir de então seria preferir as normalistas, seguindo critérios para contratação, pois a troca não era tão simples e direta, como podemos ver no seguinte trecho: “[...] o Estado cometeria uma injustiça, clamorosa, si sumariamente deslocasse, elementos dessa ordem, movido por uma regra geral de permutar as leigas por diplomadas".

Uma das possibilidades para pensar a formação de professores rurais foi publicado no mesmo jornal O Dia (1932 edição $\mathrm{n}^{\circ}$. 2452), as Bases para a organização do ensino complementar, normal ${ }^{14}$ e normal superior, onde aparece uma especialização para a escola rural onde os alunos do $2^{\circ}$ ano devem realizar cursando ao menos um semestre. Esta especialização conta com: a) Agricultura e indústrias rurais; b) Organização escolar, métodos

\footnotetext{
${ }^{12}$ Todas as citações, diretas ou indiretas, que foram feitas a partir dos periódicos mantém a linguagem original.

${ }^{13}$ Jornalista e professor que contribuiu muito com a imprensa paranaense e foi um dos signatários do Manifesto dos Pioneiros da Educação Nova de 1932. Para maiores informações ler artigo de Eliezer Feliz de Souza intitulado Trajetória e discursos educativos do jornalista e professor Raul Rodrigues Gomes na imprensa Paranaense (1907 - 1975) publicado na IX ANPEd Sul de 2012.

${ }^{14}$ Ainda segundo as Bases da organização (Art. 26), cada Escola Normal terá anexos ou a ela subordinados: um jardim de infância, um grupo escolar, uma escola rural isolada, um grupo escolar rural, uma escola complementar, uma oficina de carpintaria, terno e modelagem, um campo de cultura para trabalhos agrícolas e pequenas indústrias e uma cantina para fornecimento de merenda aos alunos a preço mínimo.
}

RIAEE - Revista Ibero-Americana de Estudos em Educação, Araraquara, v. 16, n. 4, p. 2663-2681, out./dez. 2021. e-ISSN: 1982-5587 DOI: https://doi.org/10.21723/riaee.v16i4.13725 
e processos aplicáveis nas escolas rurais; a escola rural e o meio e c) Prática do ensino em escola rural.

No jornal Diário de Tarde (1930 edição no. 10735) temos a indicação de um Curso Profissional Rural que será ministrado às moças filhas de agricultores do interior do estado, sabendo da necessidade de alicerçar a prática intensa da agricultura em um país que se ampara na vida "sadia do campo". Ressalta ainda que o ensino agrícola sistematizado e valorizado deve merecer especial cuidado dos nossos dirigentes.

Em meados de 1943 temos um poema que fala da professora da escola rural retratada como heroína. Sabemos que, durante muito tempo, o magistério representava praticamente a carreira exclusiva aberta às mulheres, tendo como segunda opção a enfermagem, já que as responsabilidades femininas não deveriam ultrapassar as fronteiras do lar, nem objetivar um salário. A dificuldade de amplo acesso às demais profissões fez da docência a opção mais apropriada para o sexo feminino, e isso foi potencializado pelos atributos de missão e vocação (ALMEIDA, 2006).

Professorinha de escola rural... Moça bonita que se levanta mais cedo do que o sol, que segue pelas estradas úmidas de orvalho rumo à casinha branca de cal onde a molecada das fazendas visinhas forma uma fila de farrapos, remendos e barrigas arredondadas de anquilostomo.

Menino! Eu já disse pra você tomar remédio.

Heroina obscura de todos os dias, mocidade crucificada, mãe prematura de filhos alheios que espeta no ar sonolento das classes preguiçosas, num gesto símbolo, contra o analfabetismo, uma régua de pau. Vamos! Abram o livro!...

Moça bonita de olhos sonhadores e taciturnos que sonha romances tropicalissimos, envenenados pelo mormaço perigoso que se infiltra no sangue, que mexe nos músculos que vibra na carne, que canta na alma, que embala nas noites compridas, povoadas de zumbidos dos pernilongos...

Parece me ver, ante a carteira, o vulto moreno, de olhar quente, brilhando, a vo macia, cansada, perguntar um pouco da taboada. Um e um?

E, num recolhimento demorado, intimo, assim como quem sonha acordado, ela vê o jardim, a banda que toca no jardim e o namorado.

Professorinha bonita, heroína obscura de todos os dias, eu queria, mas queria mesmo, erguer uma estátua para você...Para você...pra mim...porque eu também já perguntei muitas veses. Um e um? (RIO NEGRENSER ZEITUNG, 1943, edição n. 816).

Esta vocação faz com que a "professora ali objetivada não se parece com um ente real, de carne e osso, com necessidades concretas, desejos e ambições. Os atributos que lhe são creditados permitem imaginá-la como um ser quase divino" (FISCHER, 2009, p. 327). Há ainda uma relação da professora com a mãe dos filhos alheios, e o grande problema dessa ligação tão direta entre docência e maternidade está nas concepções estereotipadas com 
relação à mulher, que acabam por reforçar mitos e preconceitos, reforçando o lugar social naturalizado das mulheres.

Há pouca menção em meados de 1930 sobre a formação do/a professor/a rural, e isso só aparece novamente nos jornais investigados depois de 1943 em forma de caricatura de uma professorinha de escola rural, e também a defesa da criação de uma Universidade Rural e Técnica no Paraná que não se efetivou.

No que diz respeito a eventos, foi possível identificar alguns congressos, semanas, seminários e conferências dedicadas à questão rural. No jornal O Dia (1934, edição n. 3322) Congresso de Educação Rural, onde apresenta o evento com a temática da educação rural que aconteceu na Bahia, com a ausência do Paraná, que não enviou representante direto; tal evento foi promovido pela Sociedade Amigos de Alberto Torres.

Na matéria a afirmação primeira é de que a educação rural é um problema pouco, mal ou não estudado, sendo que a escola rural espalhada pelo Brasil se caracteriza mais ou menos inútil para a função elevadíssima que deveria desempenhar por ser "meramente verbalista, é desambientada. E seu professor a ocupa displiscentemente, tendo seus magros rendimentos como mero ganha pão".

No mesmo jornal O Dia (1937, edição n. 4101) há uma matéria sobre o Congresso de Ensino Rural promovido pela Sociedade "Luiz Pereira Barreto”, que foi inspirado na orientação da Sociedade dos "Amigos de Alberto Torres", que organizou o Congresso de Ensino Rural realizado na Bahia em 1934. As problematizações e discussões do Congresso giram em torno das seguintes questões: Que diferença existe entre a escola rural e a urbana? Há diferença entre as escolas destinadas ao preparo da população rural, da zona agrícola e pastoril? Praieira e fluvial? Merece cuidado especial o problema de saúde na zona rural? Deve ou não ser a nossa escola primária uma escola de trabalho? Como organizar a escola normal para a formação de professores de escolas regionais?, expressando uma clara preocupação com a formação do mestre para a zona rural.

No Jornal Paraná-Norte (1948, edição n. 892) publicado em 4 de junho tem uma matéria sobre a Semana Ruralista de Londrina. Tais Semanas Ruralistas vem sendo promovidas em todo o território nacional pelo Serviço de Informação Agrícola e visam promover a melhoria das condições de vida dos agricultores. Durante as Semanas Ruralistas são efetuados, também, cursos rápidos para professoras primárias, no interesse de facilitar, quanto possível, a organização e orientação dos Clubs Agrícolas Escolares, base da formação dos futuros agricultores do Brasil. Nestes cursos, os seguintes temas são abordados: indústrias 
rurais caseiras, jogos e brinquedos para a infância rural, a tarefa da educação rural, combate à saúva, pomar doméstico e escolar, clubs agrícolas escolares e sericultura.

No jornal A Tarde (1950, edição n. 136), ao tratar do Seminário da Educação Rural, "[...] conceituam a Educação Rural como sendo aquela que se ajusta à realidade da vida do campo, sendo que a escola rural se caracteriza antes pela natureza do ensino que pela localização". Além disso, incluíram o que chamaram objetivo social e econômico da Educação rural, qual seja, contribuir para a fixação do homem ao campo, elevando-lhe os padrões de vida, mostrando-lhe como viver feliz e utilmente no seu próprio meio e trazendo para o ambiente rural, sem deformar a essência deste, as conquistas da técnica e do progresso.

No que se refere à função e representação da escola rural temos o jornal O Estado (1936, edição 19) com a matéria sobre A função da Escola Rural que indica que para que a escola rural possa desempenhar a função que lhe é essencial, é preciso que se transforme radicalmente. "É bem verdade que, entre nós, não existe a verdadeira escola rural. O que há são escolas apenas denominadas ruraes, pela só circunstância de se localizarem nos sítios, fazendas ou povoados".

[...] São instituições segregadas do ambiente e cuja actividade se enclausura entre as paredes da sala de aula. Programmas, horarios, material de ensino, mobiliário, livros e que mais, tudo identifico ao da escola urbana, embora em proporções mais modestas, porque a escola da roça, diz-se, tem menores exigências...

Ora, com a organização que se lhes imprimiu, nossas chamadas escolas ruraes jamais desempenharão o papel que devem exercer. Hão de persistir, infelizmente, como simples nucleos de semialphabetização da infância, pelo que é lícito inquirir se não estarão, de certo modo, concorrendo para infelicitar as populações campezinas com apenas entreabrir-lhes, mal a mal, os segredos do abc e abandoná-las, depois à própria sorte.

Não se trata, evidentemente, nessa questão da ruralização das escolas 'ruraes', de montagem, installações, etc. Isso nada mais é do que aspecto exterior e material do problema, a exigir dinheiro. O de que se há de cuidar, principalmente, com afan e enthusiasmo, é do espírito que precisa vitalizar a escola roceira. Cumpre dar a esta uma alma rural, que lhe tem faltado, desgraçadamente. [...] (O ESTADO, 1936, edição n. 19) ${ }^{15}$.

A chamada 'escola da roça', segundo as representações deste jornal, faz jus à acepção pejorativa dessa denominação porque é caracterizada muito próxima ao modelo urbano e com instalações ainda mais precárias.

No que tange sobre organização da educação rural O Dia (1932, edição n. 2669) há uma matéria sobre Educação rural escrita por Raul Rodrigues Gomes que trata do problema dessa modalidade de ensino que "acham-no simples, pueril, elementar e julgam removê-lo,

${ }^{15}$ A escrita nas citações diretas acompanha a ortografia da época.

RIAEE - Revista Ibero-Americana de Estudos em Educação, Araraquara, v. 16, n. 4, p. 2663-2681, out./dez. 2021. e-ISSN: 1982-5587 
criando e promovendo escolas isoladas". Segundo a reportagem a criação de escolas isoladas não resolveria o problema, pois a realidade contrasta e "[...] cada escola rural, deserta de atividade, absolutamente erradicada de ambiência, desempenha mecânica e precariamente sua rudimentaríssima função de ensinar o abc, condimentado sovinamente de vestígios de calculo e de hieroglífica escritura".

A solução para a educação rural não estaria apenas na abertura de escolas, multiplicando seu número por todo o Estado e pelo país, mas também no melhoramento profissional do corpo docente para área rural; isso implica uma dupla atuação "[...] duma parte, erguer o nível intelectual e tecnico do magisterio, e doutra parte provocar, estimular e ampliar o melhoramento espiritual e moral das sociedades campesinas, mergulhadas na mais deplorável miséria mental”. Ainda no jornal O Dia (1938, edição n. 4623) há outra reportagem sobre a Educação rural na campanha da desanalfabetização defendendo que só será possível tornar eficiente o ensino entre os filhos de colonos preparando um magistério especializado.

O professor Sud Mennucci ${ }^{16}$ foi uma figura bem conhecida nos jornais, apareceu no jornal O Dia (1935, edição n. 3587) para tratar da conferência que ele realizou na universidade sobre o tema 'Porque eu sou ruralista', tecendo suas principais idéias sobre o problema da educação rural no Brasil. Apareceu também no ano seguinte no jornal O Estado (1936, edição n. 29), justificando O porque do ensino rural (Sud Menucci), onde apresenta o plano da ruralização do ensino assentado em três pontos cardiais:

a) o do reconhecimento da existência de grupos humanos differenciados quanto às suas actividades, grupos esses que, por sua localização, por suas características e contrastes, estabelecem o equilibrio das massas sociaes de uma nação;

b) o da necessidade de prevenir e evitar a intercorrencia desses varios grupos entre si, de forma que nenhum delles prefira ou aspire à maneira de vida do outro;

c) o de dar a cada um desses grupos sociais a noção da necessidade de sua própria existência tal como é.

O primeiro ponto exigirá que se ministre a cada um desses aglomerados o tipo de educação mais adequada a seu meio. Segundo ele inventou-se uma escola-padrão, a da cidade, e esta foi espalhada por todas as zonas na defesa de que a escola devia ser única, sem levar em consideração as especificidades de cada espaço, porque se dispensar ao campo o mesmo

${ }^{16}$ Nasceu em 1892 em Piracicaba, foi educador, sociólogo, jornalista e escritor e um dos maiores defensores das causas rurais. Para saber mais ler a tese de SANTOS, Fernando Henrique dos Santos. A vida do pensamento e o pensamento da vida: Sud Mennucci e a formação de professores rurais, defendida na Universidade de São Paulo em 2015.

RIAEE - Revista Ibero-Americana de Estudos em Educação, Araraquara, v. 16, n. 4, p. 2663-2681, out./dez. 2021. e-ISSN: 1982-5587 
tratamento que dão as cidades, de modo que a zona rural não tenha empecilhos para obter, por exemplo, a energia elétrica, teremos assegurada a fixação dos homens à terra. Com isso, daremos a oportunidade de "tornar cada vez mais attrahente e mas encantador e teremos supprimido o sentimento de inferioridade, de quase inveja, que leva os camponios e litoranes em busca das grandes urbes".

No jornal A Divulgação (1948, edição n. 3-4), Ensino Rural no Paraná, temos dados da Secretaria de Agricultura, Indústria e Comércio, referentes à década de 1940 que indicam a manutenção de 9 Escolas Rurais, das quais 7 de Trabalhadores Rurais e 2 de Pescadores, todas elas supervisionadas pelo Departamento de Ensino Superior, Técnico e Profissional.

Temos ainda o registro sobre a instalação de classes de ensino supletivo em fazendas e sítios por iniciativa dos proprietários, que aparece no jornal Paraná Norte (1949, edição n. 948) na reportagem sobre $A$ campanha de Educação de Adultos na zona rural, o objetivo seria instalar cursos especiais a fim de que neles sejam matriculados aqueles que na idade própria não conseguiram frequentar escola primária. O professor era um colono mais experimentado, de nome Pedro. Este cuida dos seus afazeres durante a manhã e depois do almoço entrega-se aos trabalhos de alfabetização. Segundo a matéria, Pedro, que tem apenas o curso primário completo, é vivo e inteligente, conseguiu já apreciáveis resultados na sua classe, graças ao interesse que têm os seus alunos, ao esforço do professor e à boa vontade do fazendeiro. "Graças a essa cooperação espontânea e patriótica é que se vai combatendo o analfabetismo naquela região".

Há ainda as reivindicações acerca de instalações de Escolas Normais Rurais, como consta no jornal Paraná Norte (1950, edição n. 986) na reportagem Uma Escola Normal Rural para Londrina, onde informa que o Ministério da Educação pretende fundar 17 Escolas Normais Rurais, espalhadas por diversos estados, e que o Paraná será um dos contemplados, visto que sua população tem aumentado consideravelmente, principalmente na região Norte, onde a cidade de Londrina se destaca e por isso justifica a solicitação de instalação de uma escola neste espaço.

No que tange à fixação do homem ao campo há diversas menções sobre a importância fundamental de formar uma mocidade rural capaz de compreender as necessidades do campo, que seja oferecida uma educação que possa reter o êxodo rural e manter a população rural onde é preciso. Isso pode ser observado no jornal O Dia (1930, edição n. 2630) na reportagem sobre $A$ educação do lavrador precisa do auxílio da nação inteira - onde apresenta uma entrevista com Dr. Carlos F. Chardon (Diretor do Departamento da Agricultura e Trabalho de Porto Rico). 
Para manter a população rural onde é preciso, no jornal O Dia (1930, edição n. 2568) publicado na edição da manhã de domingo, dia 8 de junho, Leôncio Correia ${ }^{17}$ escreveu um artigo intitulado A Semana de Educação onde ele trata os três princípios fundamentais com que se conformam os grandes sistemas de organização escolar: o princípio da comunidade, da escola única e da escola do trabalho. E define a escola da seguinte forma:

[...] o princípio de localização do ensino ou sua adaptação ao meio, que manda amoldar as escolas primárias às singularidades da zona a que servem, sem quebra da sua unidade fundamental, nas suas bases humanas e nacionaes. A escola primária, com as suas officinas de pequenas industrias, na zona urbana, com seus campos de experiências agrícolas em zona rural, ou com seus modestos museus de aparelhos de pesca, na região marítima, longe de desviar da lavoura e da pesca para os centros fabris ou das industrias para as letras, a população infantil que acolhe, vae assim ao encontro do que deverá ser, ao mesmo tempo que a instrução, o seu fim principal: enraizar o operário às oficinas, o lavrador à terra e o pescador às praias, fazendo-os compreender e amar, com o trabalho produtivo, a vida intensa das fábricas, a tranqüila vida rural ou a vida valorosa das grandes pescarias [...] (O DIA, 1953, edição n. 2568).

O discurso pela construção de uma malha viária no estado aparece no jornal O Dia (1937, edição n. 4308) com um título emblemático: Criar escolas e abris estradas - eis a preocupação capital que tem caracterizado a gestão de Manoel Ribas ${ }^{18}$ em discurso proferido aos prefeitos reunidos em Curitiba. Afirma ele: “[...] eu vos posso afirmar que a minha constante preocupação é crear escolas e abrir estradas, ligando todos os municípios entre si, para uma perfeita comunhão de idéas e para maior grandeza do Paraná”.

Manoel Ribas, assim como Moysés Lupion posteriormente, priorizou em sua gestão, as questões ligadas ao rural. Em seu discurso Manoel Ribas assegura que "[...] a riqueza de um país, ou de um Estado, vem da terra. Daí a minha predileção ruralista. E é esta terra das araucárias que há de proporcionar num futuro bem próximo a emancipação econômica do Paraná”.

${ }^{17}$ Advogado, escritor, jornalista e político nascido em Paranaguá - PR e foi diretor da Instrução Pública do Rio de Janeiro, diretor do colégio Pedro II, diretor da Imprensa Nacional, diretor do Instituto de Educação do Rio de Janeiro, deputado federal e deputado estadual pelo Paraná,

${ }^{18}$ Manoel Ribas foi interventor nomeado por Getúlio Vargas para administrar o Estado do Paraná. Permaneceu de 1932 a 1945 à frente do governo paranaense, ora como interventor (1932-1934), ora como governador de (1935-1937), e outra vez como interventor (1937-1945). 


\section{Considerações finais}

Uma das motivações para a construção deste repertório encontra-se na intenção de contribuir com a área de História da Educação no Estado do Paraná, especificamente no que tange a temática rural, considerando que este Estado foi predominantemente rural até 1960 e este passado rural ainda é pouco explorado em termos escolares, de estrutura, de formação de professores e de práticas educativas para o meio rural.

O repertório sobre a educação rural paranaense expõe um patrimônio educacional vasto a ser explorado por meio da imprensa, e estes conjuntos de materiais apresentados constituem uma via de acesso importante às mais variadas informações que podem ser abordadas de várias maneiras: o significado que a educação rural assumiu no estado do Paraná ao longo do século XX; a forma como a educação rural foi priorizada (ou não) e como isso teve impacto no desenvolvimento do estado; os objetivos diversos da educação rural, apresentados nos diferentes periódicos; a forma como o estado atendia a demanda pela educação rural, sua estrutura e formação de professores para o meio rural.

Neste repertório a educação rural foi apresentada dividida em cinco seções: formação do professor rural; eventos; função e representação da escola rural; organização da educação rural e fixação do homem no campo, catalogando reportagens sobre a temática em nove jornais distintos (O Dia; Diário da Tarde; Rio Negrenser Zeitung; Diário do Paraná. Paraná Norte; A Tarde; A Divulgação; O Estado e Paraná Esportivo) entre os anos de 1930 e 1961. Neste período há a defesa de uma educação própria ao homem do campo, que possa ter estrutura adequada e professores preparados para lidar com a questão rural, este tripé contribuiria para a fixação do homem à terra.

\section{REFERÊNCIAS}

ALMEIDA, J. S. Mulheres na educação: missão, vocação ou destino? In: SAVIANI, D.; ALMEIDA, J. S.; SOUZA, R. F.; VALDEMARIN, V. T. O legado educacional do século XX no Brasil. Campinas, SP: Autores Associados, 2006. p. 59-108.

BASTOS, M. H. C. O Novo e o Nacional em revista: A Revista do Ensino do Rio Grande do Sul (1939-1942). Tese (Doutorado em Educação) - Universidade de São Paulo, 1994.

CARVALHO, M. M. C. Uso de impresso nas estratégias católicas de conformação do campo doutrinário da pedagogia (1931-1935). Cadernos ANPEd, Belo Horizonte, n.7, 1994.

CASPARD, P. (Dir.). La presse d'éducatio et d'enseignement, XVIII siécle 940. Repertoire Analytique. Paris: CNRS-INRP, 1981-1991. 
CATANI, D. B. A imprensa periódica educacional: as revistas de ensino e o estudo do campo educacional. Educação e Filosofia, Uberlândia, v. 10, n. 20, p. 115-130, jul./dez. 1996.

CATANI, D. B. Educadores à meia-luz: um estudo sobre a Revista de Ensino da Associação Beneficente do Professorado Público de São Paulo (1902-1919). 1989. Tese (Doutorado) Faculdade de Educação, Universidade de São Paulo, São Paulo, 1989.

CATANI, D. B.; BASTOS, M. H. C. (org.). Educação em Revista: a imprensa periódica e a história da educação. São Paulo: Escrituras Editora, 2002.

CATANI, D. B.; SOUSA, C. P. (org.). Imprensa periódica educacional paulista (18901996): Catálogo. São Paulo: Editora Plêiade, 1999.

CATANI, D. B.; SOUSA, C. P.. A imprensa periódica educacional e as fontes para a História da cultura escolar brasileira. Revista do Instituto de Estudos Brasileiros, v. 37, p. 177-183, 1994. Disponível em: http://www.revistas.usp.br/rieb/article/view/71310. Acesso em: 03 mar. 2017.

CHARTIER, R. A história cultural: entre práticas e representações. Lisboa/Rio de Janeiro: Difel / Bertrand Brasil, 1990.

CORREIA, A. P. P. Escolas Normais: contribuição para modernização do Estado do Paraná (1904 a 1927). Educar em Revista, Curitiba, n. 49, p. 245-273, jul/set, 2013.

FARIA, T. B. Paraná, território de vocação agrícola?! Interiorização do curso Normal Regional (1946-1968), 2017. Tese (Doutorado em Educação) - Universidade Estadual de Maringá, Maringá, 2017.

FERNANDES, A. L. C. O impresso e a circulação de saberes pedagógicos: apontamentos sobre a imprensa pedagógica na história da educação. In: MAGALDI, A. M. B. M.; XAVIER, L. N. Impressos e História da Educação: usos e destinos. Rio de Janeiro: 7Letras, 2008.

FISCHER, B. D. A professora primária nos impressos pedagógicos (1950-1970). In: STEPHANOU, M.; BASTOS, M. H. C. (org.). Histórias e memórias da educação no Brasil. 3. ed. Petrópolis, RJ: Vozes, 2009. v. III, p. 324-335.

GIL, A. C. Técnicas de pesquisa e elaboração de monografias. 4. ed. São Paulo: Atlas, 2002.

NÓVOA, A. A imprensa de educação e ensino: repertório analítico (séculos XIX e XX). Lisboa: Instituto de Inovação Educacional, 1993.

NÓVOA, A. A imprensa de Educação e Ensino: concepção e organização do repertório português. In: CATANI, D. B.; BASTOS, M. H. C. (org.). Educação em Revista: a imprensa periódica e a história da educação. São Paulo: Escrituras Editora, 2002.

PALLARES-BURKE, M. L. G. A imprensa periódica como uma empresa educativa no século XIX. Caderno de Pesquisa, n. 104, p. 144-161, jul. 1998. 
RODRIGUES, E. A imprensa pedagógica como fonte, tema e objeto para a História da Educação. Fontes e métodos em História da Educação. Dourados, MS: Ed. UFGD, 2010. p. 311-325.

SCHELBAUER, A. R. Da roça para a escola: institucionalização e expansão das escolas primárias rurais no Paraná (1930-1960). História da Educação, Porto alegre, v. 18, n. 43, maio/ago. 2014.

SCHELBAUER, A. R.; CORREA, R. L. T. Expansão e modalidades de escola primária rural no estado do Paraná: iniciativas de governos estadual e federal de 1930-1960. In: CONGRESSO LUSO BRASILEIRO DE HISTÓRIA DA EDUCAÇÃO, 7., 2013, Cuiabá. Anais [...]. Cuiabá, MT, 2013. Disponível em: http://sbhe.org.br/novo/congressos/cbhe7/. Acesso em: 18 set. 2015.

\section{Como referenciar este artigo}

IVASHITA, S. B. Repertório de pesquisa sobre a educação rural no paraná por meio da imprensa (1930-1961). Revista Ibero-Americana de Estudos em Educação, Araraquara, v. 16 , n. 4, p. 2663-2681, out./dez. 2021. e-ISSN: 1982-5587. DOI: https://doi.org/10.21723/riaee.v16i4.13725

Submetido em: 16/07/2021

Revisões requeridas em: 15/08/2021

Aprovado em: $12 / 09 / 2021$

Publicado em: 21/10/2021 